\title{
Current concepts of the morphology and biology of Treponema pallidum based on electron microscopy
}

\author{
N. M. OVČINNIKOV AND V. V. DELEKTORSKIJ
}

Department of Microbiology, Central Research Institute of Skin and Venereal Diseases (Director: Prof. N. M. Turanov), Ministry of Health, Moscow, USSR

The development of electron microscopy has advanced our knowledge of the morphology of Treponema pallidum, but the exact significance of some of the formations observed is not yet clear and requires further detailed study by chemists as well as morphologists. The literature has been reviewed and our methods described in previous reports (Ovčinnikov and Delektorskij, 1968, 1969, 1970a). In this paper we shall limit ourselves to a description of our most recent results.

The classic spiral shape of $T$. pallidum, with coils of regular width and depth slightly narrower towards the acuminate ends, is to be considered as typical for this organism.

We shall not reproduce here the illustrations already published in various periodicals; the photographs illustrating the present study have not previously been published.

Examination of preparations processed by the negative contrast method with a magnification X6-8000 has confirmed the fact that the thickness of the treponeme is uneven along its length, as established previously in light microscopic studies on living specimens. It has been proved that the thickness changes as the treponeme moves; this clearly shows that the body of $T$. pallidum is able to contract and, consequently, has a special apparatus for this purpose.

With greater magnification it can be seen that in young cultures the body of the treponeme is covered by a transparent mass forming a wide mucoid sheath (Ovčinnikov and Delektorskij, 1969). In older cultures this sheath cannot be demonstrated, and the question of its origin (i.e. whether it is a product of the treponeme or derives from the host tissues) should be studied in relation to the specific localization of the organism and the conditions of its existence.

Bearing in mind certain differences in the structure of cultivated and pathogenic treponemes, we shall

Received for publication March 1971

Paper presented at the International Colloquium on the Late Treponematoses, Miami, Florida, U.S.A., on January 4-8, 1971 describe first the cultivated strains and then the pathogenic organism. A comparative study of several cultivated strains (Reiter, Kazan, and Stavropol) ir has already revealed certain variations, but they are not very significant. One end of the treponeme carries an oval formation which we have named 'head structure' (Ovčinnikov and Delektorskij, 1968, 1969). Its shape is somewhat variable and it contains basal granules, which are the sites of attachment of the fibrils and are possibly the centres controlling movement. When living treponemes are examined by darkfield microscopy this structure may exhibit a abrupt rotatory motion. The opposite end is usualle devoid of such a formation.

During certain periods of growth, probably before the division of the treponeme, the head structure is shed together with the fibrils. This head structure is plainly visible in cultivated strains, but we could not clearly discern it in the pathogenic $T$. pallidum.

The basal granules have an annular shape (Fig. 1); the fibrils that are attached to them stretch towards the opposite end of the treponeme encircling its body. We do not agree with the view that these fibrils are inserted in the ends of the treponeme or in one end only, remaining free at the opposite end. Actually, each fibril has two insertions: one into a basal granule at one end of the treponeme and the other into some other part of its body. The number of fibrils differs not only between individual specimens but throughout the body of a single treponeme; in the middle of the body one may find ten to twelve fibrils but in another part only three, and so on. When the organisms are studied by the negative contrast method the fibrils appear to lie on the surface of the treponeme and sometimes seem to be entirely free. This impression prompted some authors to suggest that $T$. pallidum lacks flagella.

Mesosomes, rounded formations of various sizes, are distributed throughout the body of the treponeme. They probably differ in their structure and functions, and are called mesosomes only because they cannot yet be further indentified. 
The treponeme has a granular surface, and delicate parallel bands course along its body.

In pathogenic treponemes (Nichols, I, Budapest strains) studied by the negative contrast method, the terminal formations at the two opposite ends differ radically in structure. One end of the organism is acuminate and consists of tubular formations contained in a round cavity, but the other end is devoid of them.

Each end is provided with a spongy mass adjacent to the outer wall and with basal granules carrying fibrils.

In past years opinions have differed as to the mode of reproduction of $T$. pallidum. It has now been proved beyond any doubt that transverse fission is the main mode of reproduction. The treponeme divides into halves or undergoes multiple division. The new organisms may be so numerous that some of them measure hardly more than one coil of the original. This fact is very important, both from the purely morphological point of view, and because it testifies to the possible existence of non-spiral forms of $T$. pallidum. During the process of division into halves, an isthmus is formed; old fibrils are shed and new ones appear on either side of this isthmus, which persists for some time after the fission. Subsequently it ruptures and the residual bodies are gradually resorbed.

The possibility of longitudinal fission may be categorically denied at present. Sexual activity on the part of the treponemes cannot be ruled out, and there is some evidence to suggest this mode of reproduction.

Sometimes we may observe thick and thin specimens which are interlaced or lie in apposition. In other pairs one treponeme is dark or smooth and its partner is light or granular. It may be asked whether these are not males and females. Their bodies intertwine and come into contact over certain areas corresponding to the mesosomes which are located near the head structure. This seems to admit the possibility of sexual reproduction.

Another mode of reproduction resorted to in adverse circumstances consists in the formation of spores which subsequently develop into new treponemes. The breakdown into granules is especially pronounced under the action of penicillin and immune sera.

Of extreme importance is the ability of treponemes to form cysts under unfavourable conditions. Investigators using light microscopy have expressed divergent opinions about the existence of cysts. Positive electron microscopic evidence has been offered only by Ryter and Pillot (1963) as well as ourselves. However, Ryter and Pillot (1963) and Pillot (1965), having correctly described the cysts ('spheroids', according to their terminology) and the encystment of treponemes under unfavourable conditions, reached the unexpected conclusion that the cysts were a product of degeneration and not a means of safeguarding the existence of the organism. As a proof, they mention the fact that 'spheroids' are formed under the influence of diverse stressful factors. In our opinion, this fact affirms rather than denies the assumption that the encystment of treponemes is a protective mechanism ensuring survival in adverse circumstances.

If the stress causing encystment surpasses the adaptive capabilities of the treponeme, the organism perishes and then undergoes degeneration. If the stress is not lethal, accessory envelopes are formed and the treponemes become well encapsulated and may survive new stresses many times stronger than the initial one. Encystment as a mechanism of survival and mode of reproduction is widespread in nature, especially among protozoa.

Under stressful conditions, the treponeme 'packs' itself into a compact roll (Fig. 8) and becomes covered with a transparent mucoid capsule, which resists the penetration of drugs and antibodies. The organisms may persist in this form for a prolonged period without any reaction from the host. The encysted treponemes and the host coexist more or less peacefully, but under propitious circumstances the cysts may be transformed again into the usual spiral, which damages the cells of the host and elicits a response. We shall return to this problem in our description of ultrathin sections of cysts.

Studies of ultrathin sections of $T$. pallidum have considerably enriched our knowledge of its structure. The methods of processing the material for ultrathin sections have been described in our previous communications.

\section{Outer membranes}

In ultrathin sections (approximately 200-250 $\AA$ thick) the outer wall (me) of $T$. pallidum consists of two electron dense layers and one electron transparent layer (Fig. 2). The cytoplasmic membrane (cm) also has three layers. It is separated from the outer wall (co) by a space of varying width that contains fibrils (f). In longitudinal sections they appear punctate or elongated depending on the plane of cutting. The cytoplasmic membrane lies over the cytoplasm (c) (Fig. 4), where ribosomes (r) are suspended. Here and there light stellate or polygonal structures are visible; these are the nuclear vacuoles (N) (Figs 12 and 13). Mesosomes (M) are met with occasionally (Fig. 2), looking like laminar formations. The same structures can be found in a transverse section. 
Fibril and Mesosomes

The relation of fibrils to the outer wall is well demonstrated (Fig. 5). The bundle of fibrils (f) lies under the outer wall, but in certain stages of development of the treponeme it becomes free; probably the continuity of the outer wall is broken, or maybe this bundle stretches like a rubber band and emerges from under the wall.

At the level of a bundle of thick fibrils, the cytoplasm contains thinner dark formations, which we consider to be deep fibrils ( $f^{\prime}$ ) (Fig. 5). Formerly we interpreted them as fungiform structures, the sites of most active metabolism. Further studies of pathogenic treponemes have convinced us that these formations are fibrils arranged in a deeper layer. If the outer wall is destroyed by special treatment, numerous deep-lying fibrils become clearly visible, though they are thinner than those of the superficial layer (Ovčinnikov and Delektorskij, 1970a) (Fig. 6). Possibly they also belong to the locomotor apparatus, but effect motion in other directions than the superficial fibrils; however, we would prefer to abstain as yet from any definite conclusions.

With high magnification it can be seen that each fibril contains an axial thread with a spiral filament wound over it. In longitudinal sections the fibrils have cross-striation with periods 1-10. Cut transversely, they appear to consist of five round structures surrounding a central core.

If we compare sections of pathogenic and cultivated treponemes, we can immediately see that in a cultivated strain the bundle of fibrils is well defined and is intimately related to the overlying outer wall, while in a pathogenic organism the fibrils are arranged in a delicate bundle (Fig. 7), their outlines are indistinct, and sometimes they are not covered with the outer wall. In a cultivated treponeme, the outer wall protrudes over a bundle of fibrils. Obviously this protrusion, which is sometimes quite large, suggested to some authors the presence of an undulating membrane, but in fact $T$. pallidum has no undulating membrane. The sectioned basal granules (Fig. 1) (B) (Ovčinnikov and Delektorskij, 1966) have the shape of two concentric rings. The structure of mesosomes varies; they may be ring-shaped or may resemble cerebral convolutions. When examining sectioned mesosomes, we can clearly observe that they communicate with the exterior and are interconnected by long channels situated under the outer wall. Sometimes a mesosome has an operculum. However, it should be emphasized once more that, as far as treponemes are concerned, the term 'mesosome' evidently encompasses a number of formations performing different functions.
Cysts

Finally, a few remarks may be made about the fine structure of cysts (Fig. 8). In ultrathin sections, their structure varies (Figs 9 and 10): some of them have two or three membranes covering the treponeme, $\frac{\sigma}{\Phi}$ which are cut crosswise or longitudinally and contain all the formations characteristic for the respective of plane of section. The envelopes (mcy) are well de- $\vec{\circ}$ veloped. Moreover, a cyst may contain laminar bodies of variable dimensions; we believe that these are $\vec{\omega}$ stores of nutrients. Other cysts have one membrane and the envelopes of the treponeme cannot be clearly demonstrated or are only partly visible. Evidently such cysts have undergone degeneration and are not viable. Typical cysts are characterized by the presence of membranes and by the preservation of all the structural features of the treponeme.

Can the host harbour cysts of pathogenic treponemes? This is a problem of paramount importance. Even those authors who admit the possibility of encystment of $T$. pallidum do not consider it $\stackrel{\mathscr{\Phi}}{\square}$ likely that cysts may exist in host tissues. By means of electron microscopy we have succeeded in demong strating the presence of cysts in a rabbit chancre, and we believe that this observation is of considerable significance.

The material was taken from an 8-month-old chancre. When examining the cysts, we could distinctly see multi-layered membranes and treponemes cut in various planes.

Obviously such a membrane serves as a strong barrier to drugs.

Many interesting structural details may be revealed by the method of fracturing frozen material. This does not submit the treponemes to any extraneous influences and thus artefacts are avoided. Photomicrographs of specimens processed by this method clearly show the granular texture of the space between the cytoplasmic membrane $(\mathrm{cm})$ and the outer wall $(\mathrm{co})$. Several dissimilar formations can be seen in the head $\frac{T}{O}$ structure. Unfortunately, any speculations about their functional significance would be premature. The $N$ cross-striation of fibrils is distinctly visible.

Comparative electron microscopic studies of $T$. pallidum and $T$. pertenue have not demonstrated any clear-cut morphological differences, except for the fact that in $T$. pertenue (Fig. 11) the terminal structures are thinner and more acuminate and the mucoid sheath is so thin as to be almost non-existent.

Studies of ultrathin sections of $T$. pallidum have undoubtedly produced valuable morphological in- $\mathbb{D}$ formation, but the chief problem facing research $\frac{\overrightarrow{\mathbb{D}}}{\vec{D}}$ workers is the interaction of the treponeme with the body cells, as for instance in a chancre. A detailed 
investigation of this problem, and especially repeated examinations performed with the use of various drugs, would certainly prove rewarding.

The examination of ultrathin sections of affected tissues may shed light on the main defence mechanisms of the host, help us to understand the function of various structures both in the treponeme and in body cells, and define the role of each type of cell involved in the pathological process. Such information may also help to solve the problems of immunology in the treponematoses.

The main types of cells present in a chancre are lymphocytes, plasma cells, fibroblasts, and other connective tissue cells. Polymorphonuclear leucocytes participate to a greater or less degree in only some phases of the development of the chancre (Ovčinnikov and Delektorskij, 1970b).

Studies of an established chancre aged 3 to 8 weeks In a rabbit chancre $T$. pallidum may exist both inside and outside cells. Extracellular forms are usually situated among collagen fibres (Fig. 12). The slide shows endoplasmic reticulum (er), collagen fibrils (kl), a lysosome (l), mitochondria (mi), nuclear membrane $(\mathrm{mN})$, and a nuclear vacuole $(\mathrm{N})$. Frequently there is a light area around the treponeme ( $T$ ); thus the impression is created that collagen fibres have been locally destroyed. Longitudinal sections do not reveal any substantial difference in structure between extracellular treponemes in a chancre and organisms in a suspension prepared from a chancre or an orchitic lesion, but we often find specimens surrounded with a two- or threelayered membrane, which is situated at a certain distance from the body of the treponeme (T) (Fig. 13). What is the origin of this membrane? Is it related to the outer wall and the cytoplasmic membrane of the treponeme or does it represent an accessory envelope produced by the invading organism or the cellular elements for protective purposes? The latter supposition cannot be disproved by the extracellular localization of the treponemes, as it may be surmised that they previously existed within cells, and were then enveloped in an isolating membrane and extruded. It is more likely that, in the majority of cases, this protective envelope is formed by the treponeme or, sometimes, by a combination of the outer wall and an accessory membrane. Finally, it is possible that in a few cases the section actually shows part of an engulfed treponeme covered with a thin cellular membrane; the impression that the organism is located extracellularly is due to an artefact caused by cutting the section.

The morphology of intracellular treponemes depends on the types of cells that have engulfed them, the duration of their stay within the cells, and their viability at the moment of phagocytosis. Usually phagocytosis is not brought to completion, i.e. endocytobiosis predominates. The absorption of treponemes by the cells is clearly visualized in electron micrographs (Figs 14 and 15). The treponeme ( $T$ ) sinks into a hollow in the cellular membrane, and the membrane then closes over it. This process is commonly observed in lymphocytes, plasma cells, and endothelial cells. Macrophages usually grasp the treponemes with their numerous pseudopodia (ps).

Intracellular treponemes may be greatly altered and may undergo digestion (Figs 16, 16a, 17). An active role in this process is played by lysosomes or phagosomes (ph).

Cellular activity and the digestion of engulfed treponemes are enhanced after an injection of penicillin.

It is especially interesting to study treponemes within plasma cells. As is known, plasma cells are the main producers of antibodies and within them immune globulins are synthetized primarily by the ribosomes ( $r)$. The treponemes engulfed by plasma cells usually remain unaltered (Fig. 18), preserving all their structural features. The organisms lie outside or inside the cisternae of endoplasmic reticulum (er). It should be noted that in the latter case the ribosomes (r) are not distributed outside the cisternae but are

\section{KEY TO THE FIGURES}

\begin{tabular}{|c|c|c|}
\hline f & 一 & fibrils \\
\hline $\mathbf{f}^{\prime}$ & - & second layer of fibrils \\
\hline me & 一 & outer wall \\
\hline $\mathrm{cm}$ & 一 & cytoplasmic membrane \\
\hline co & 一 & outer envelope or 'casing' \\
\hline B & 一 & basal granules \\
\hline $\mathbf{N}$ & 一 & nuclear vacuole \\
\hline $\mathbf{M}$ & - & mesosome \\
\hline $\mathbf{r}$ & 一 & ribosome \\
\hline mcy & - & common envelope of the cys \\
\hline c & & cytoplasm \\
\hline er & - & endoplasmic reticulum \\
\hline kl & 一 & collagen fibrils \\
\hline & & lysosome \\
\hline $\mathrm{mi}$ & 一 & mitochondria \\
\hline ps & - & pseudopodia \\
\hline $\mathbf{T}$ & - & treponeme \\
\hline Tpl & & treponemes in state of lysis \\
\hline ch & - & chromatin \\
\hline $\mathrm{mN}$ & 一 & nuclear membrane \\
\hline Ks & 一 & crystalloid structure \\
\hline TL & & L-forms of treponeme \\
\hline & & ded inclusion \\
\hline $\mathbf{M}$ & & rosome \\
\hline NA & & xyribonucleic acid \\
\hline
\end{tabular}



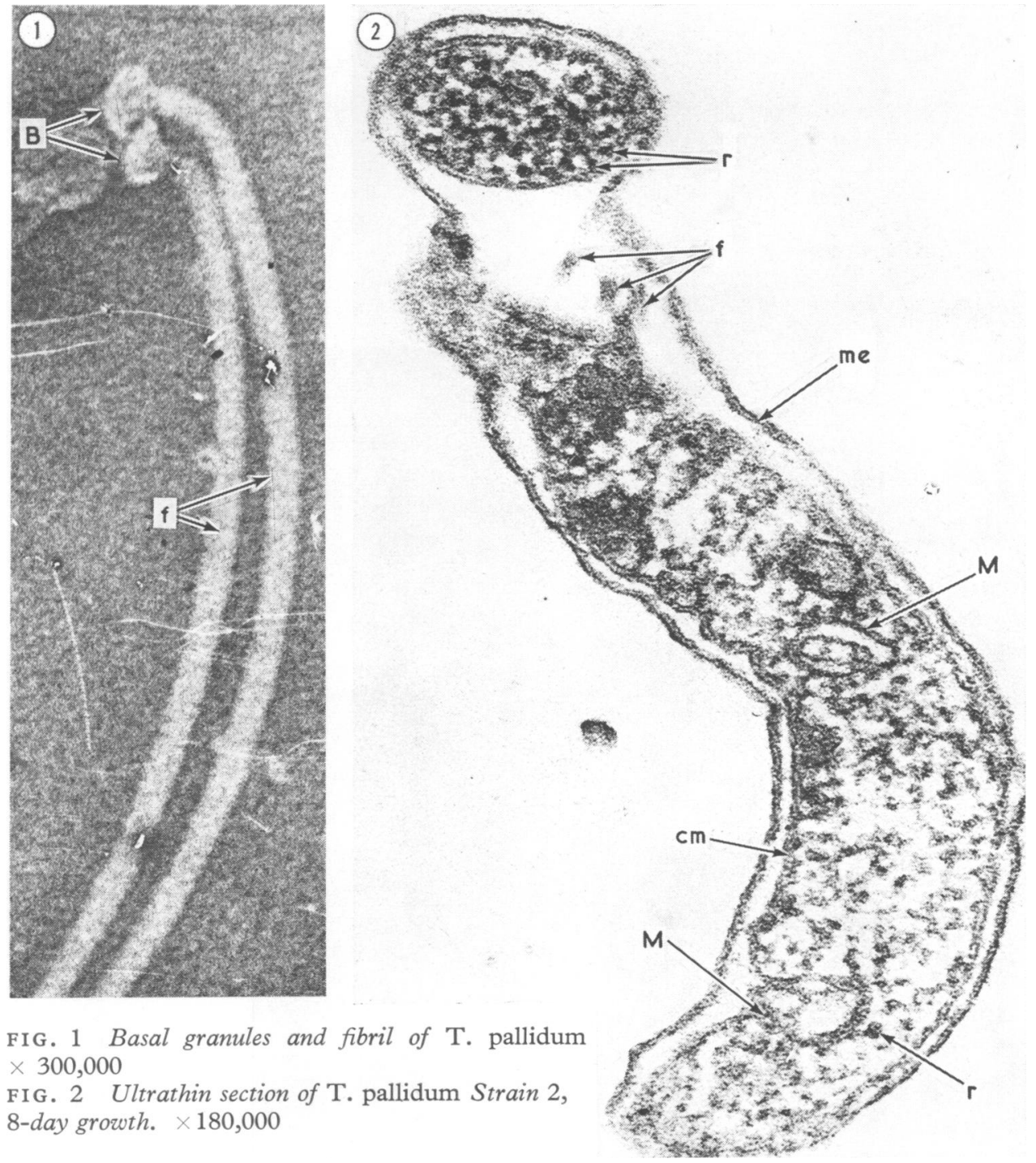

FIG. 1 Basal granules and fibril of $\mathrm{T}$. pallidum $\times 300,000$

FIG. 2 Ultrathin section of T. pallidum Strain 2, 8-day growth. $\times 180,000$

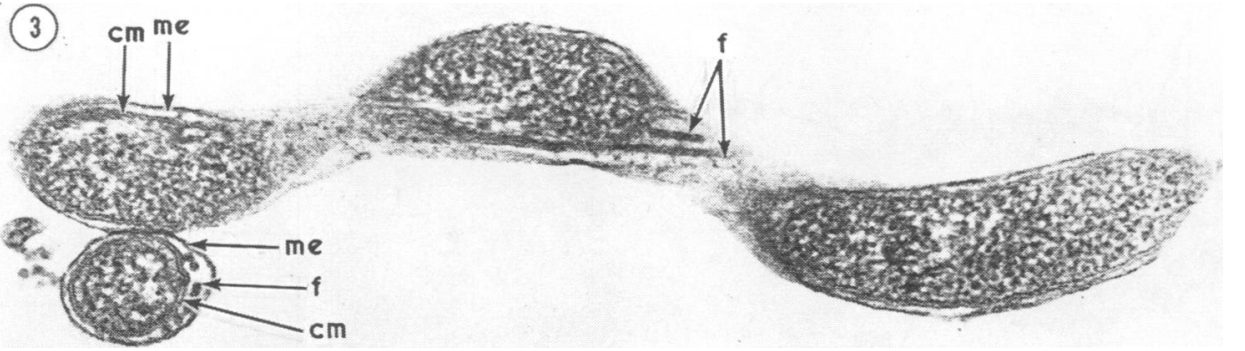

FIG. 3 Ultrathin section of T. pallidum Strain $2 . \times 80,000$ 
(4)

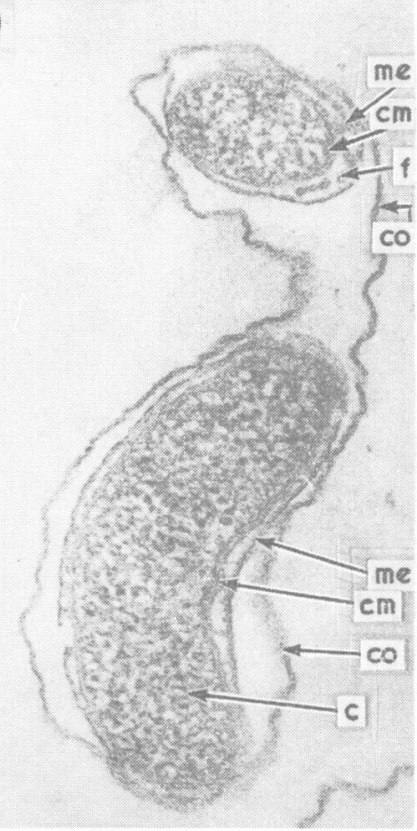

FIG. 4 Ultrathin section of $\mathrm{T}$.

pallidum. $\times 120,000$

FIG. $4 a$ Outer envelope ('casing') of treponeme clearly visible. $\times 180,000$

(5)
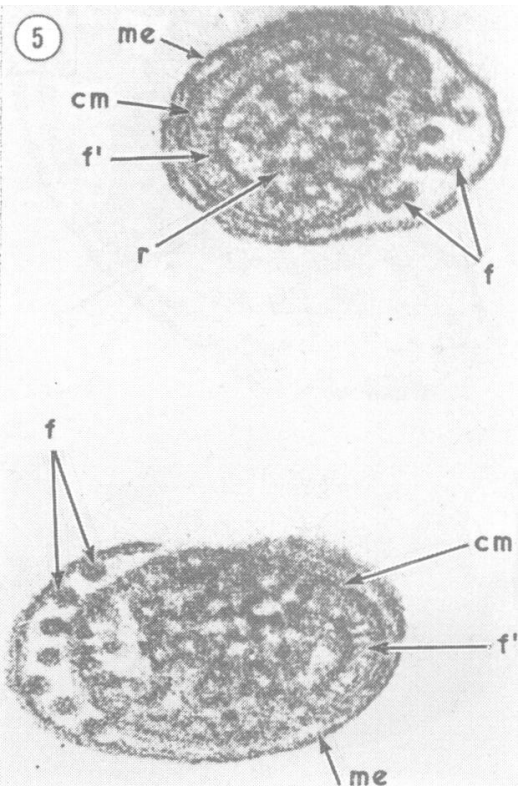

FIG. 5 Ultrathin cross-section of T. pallidum. $\times 180,000$
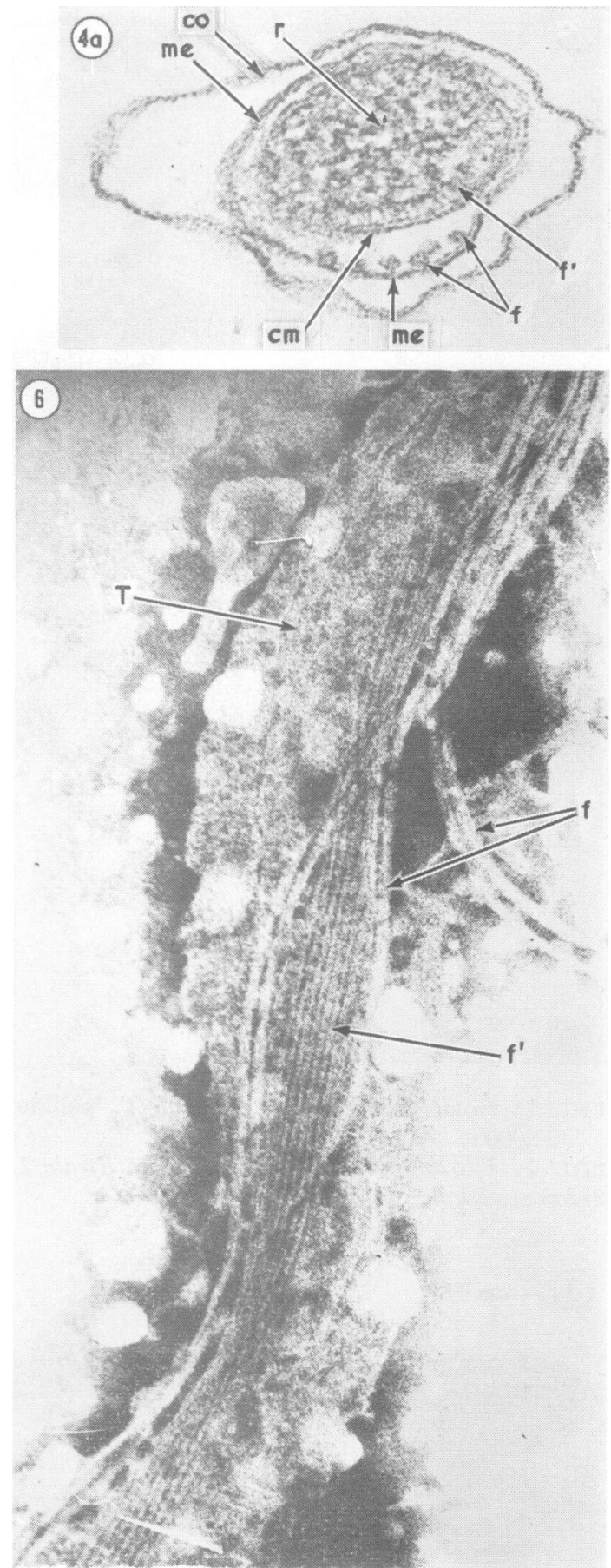

FIG. 6 Fibrils and second layer of fibrils. T. pallidum Kazan strain, 8-day growth $\times 120,000$ 


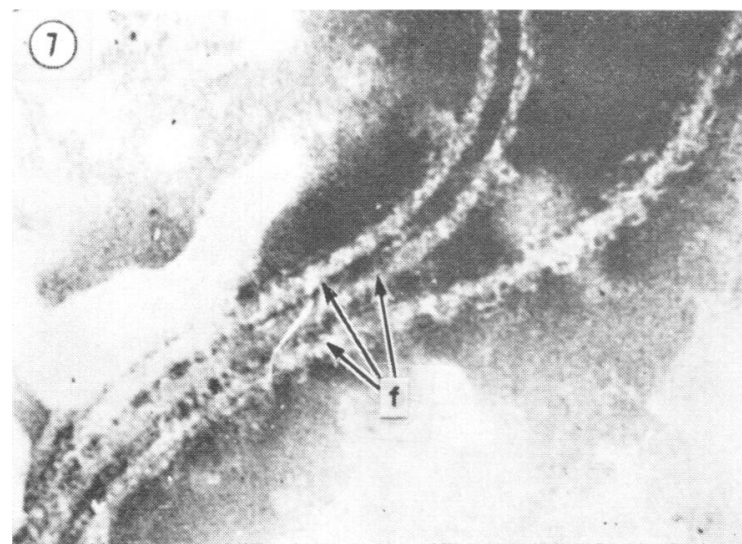

FI G. 7 Bundles of fibrils of T. pallidum. $\times 140,000$

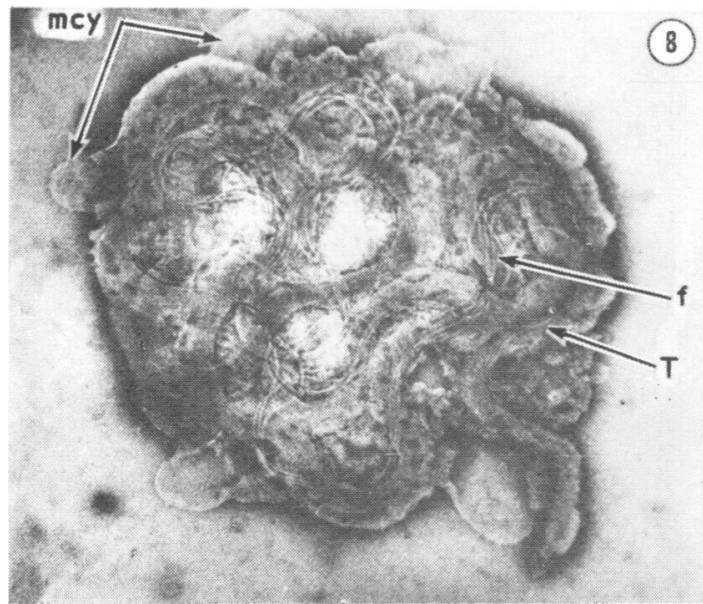

FIG. 8 T. pallidum Nichols strain from a 7-dayold orchitis. Negative-contrast method shows the organism packed into a cyst. $\times 20,000$

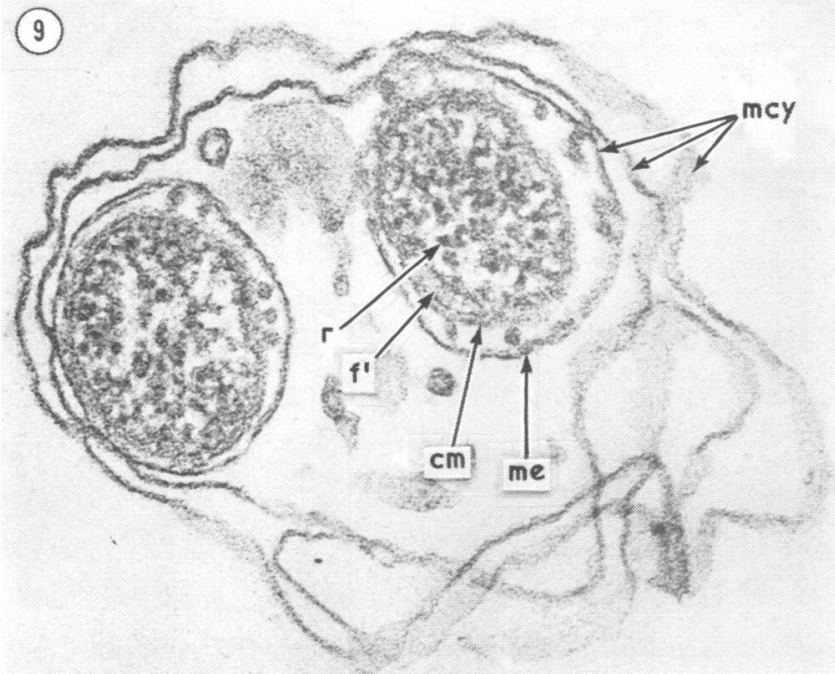

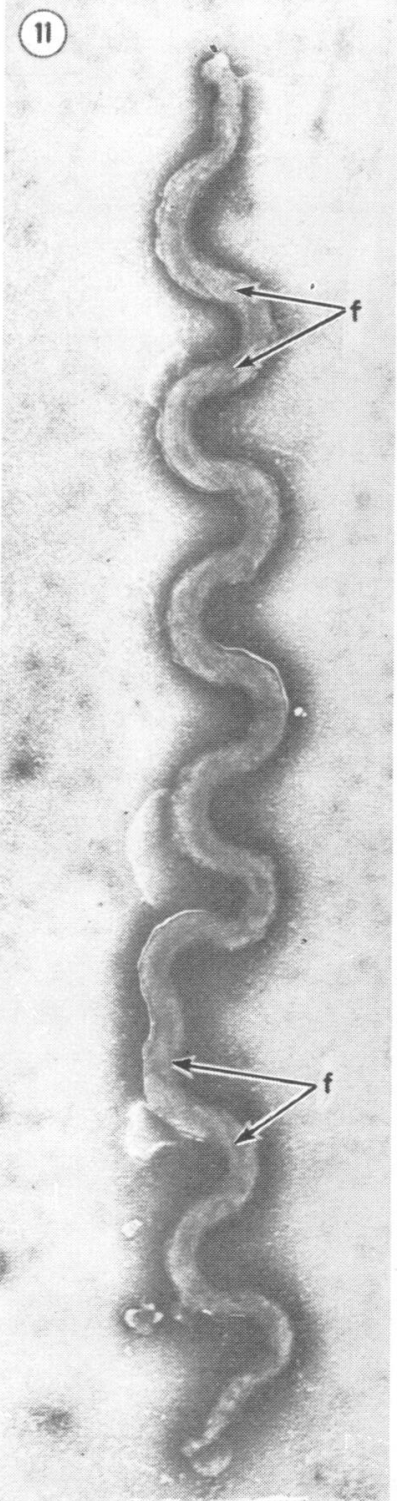

FIG. 11 T. pertenue under the electron microscope. Negative contrast method. $\times 25,000$

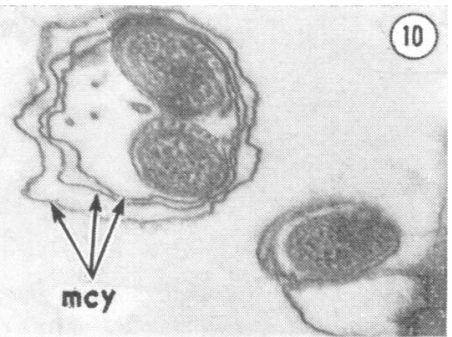

FIG. 9 and FIG. 10 Ultrathin sections of a cyst of T. pallidum. $\times 120,000$ and $\times 60,000$ 

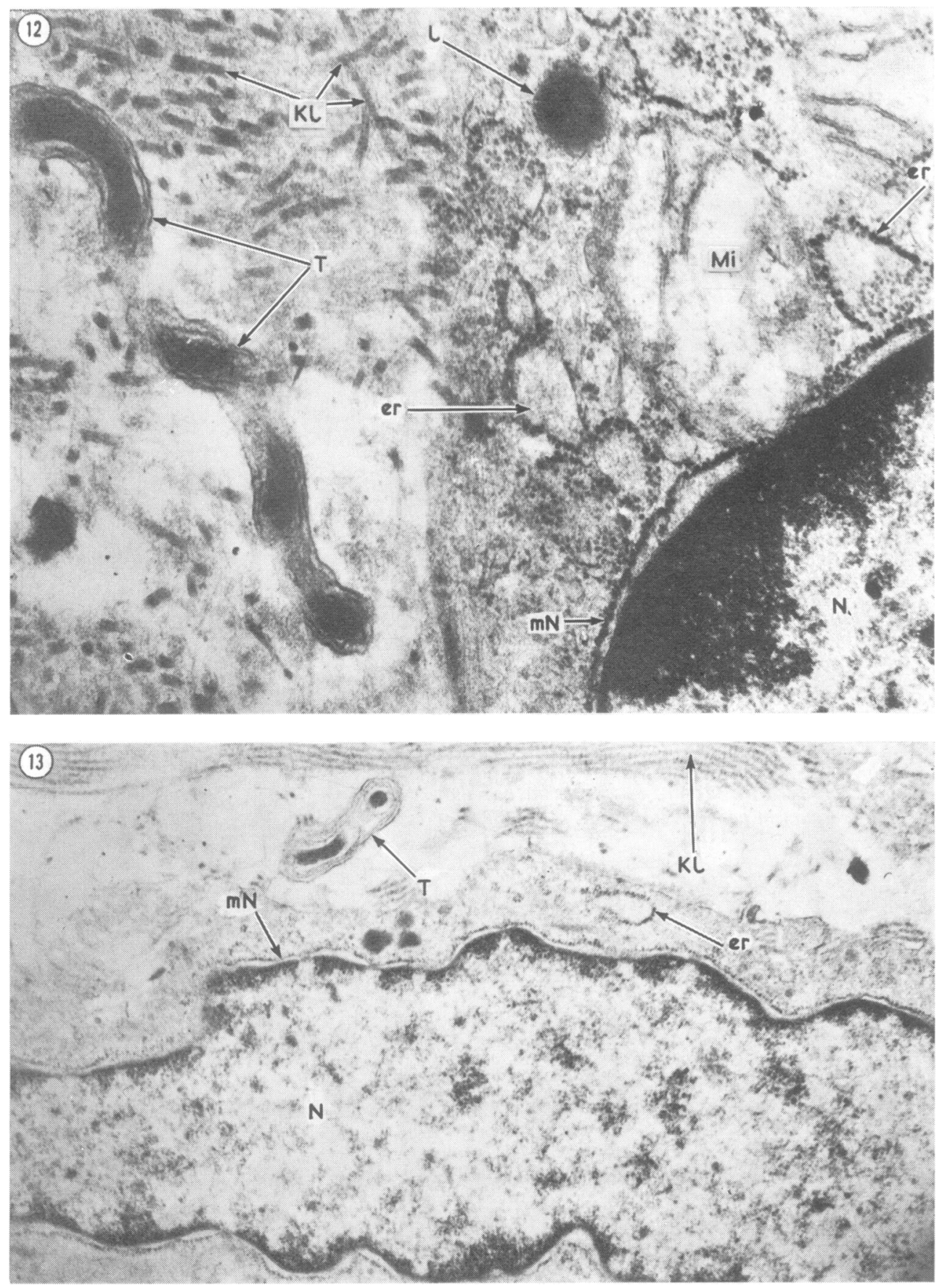

FIG. 12 Ultrathin section from a rabbit infected with Nichols strain, showing T. pallidum among collagen fibrils. $\times 50,000$

FIG. 13 Ultrathin section of Nichols strain, showing multi-layered outer wall. $\times 12,000$ 

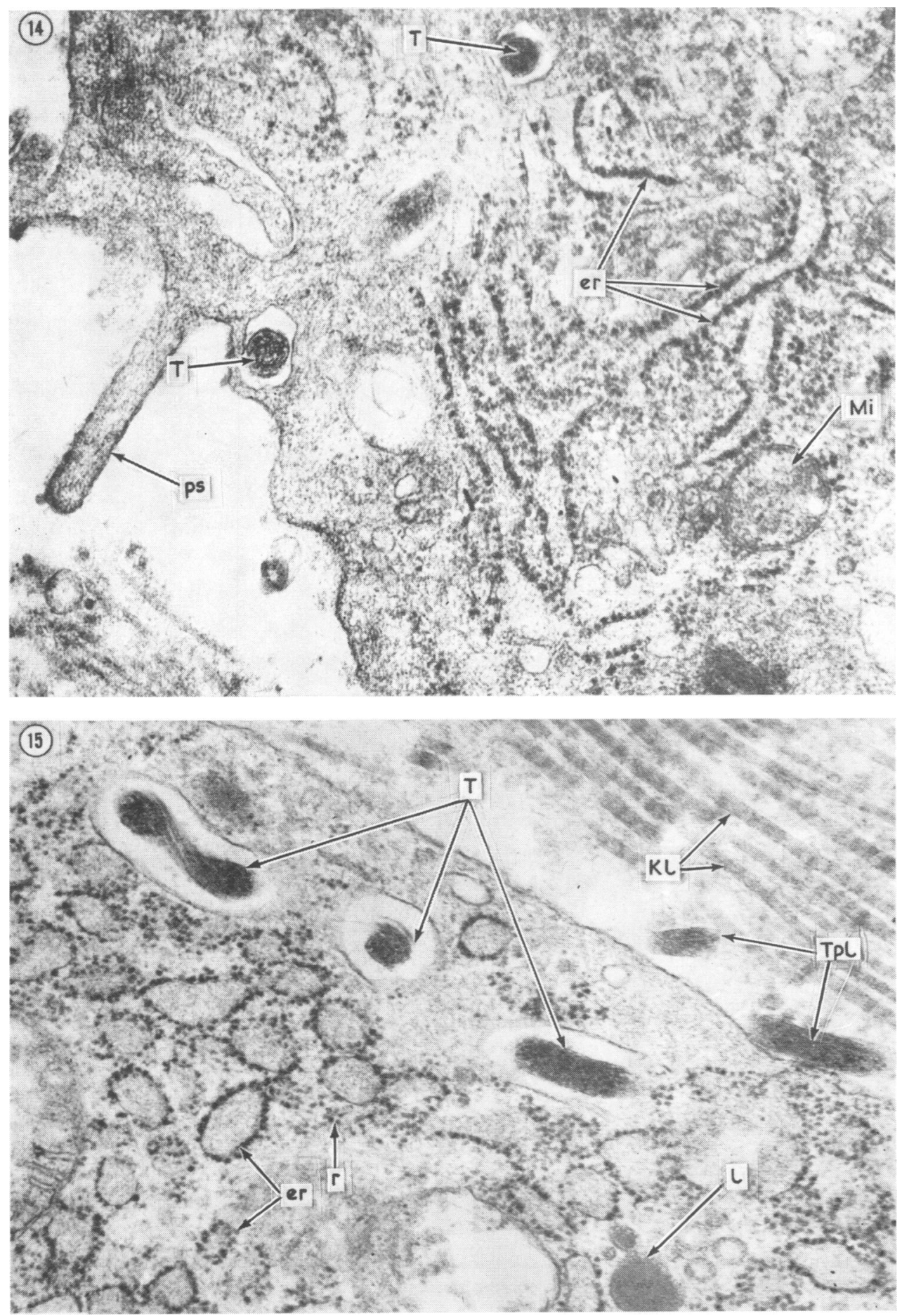

FIG. 14 Ultrathin section of material from the site of a chancre, showing intact $T$.

pallidum inside a cell. $\times 50,000$

FIG. 15 Treponemes lying outside the cell in a state of lysis. $\times 40,000$ 

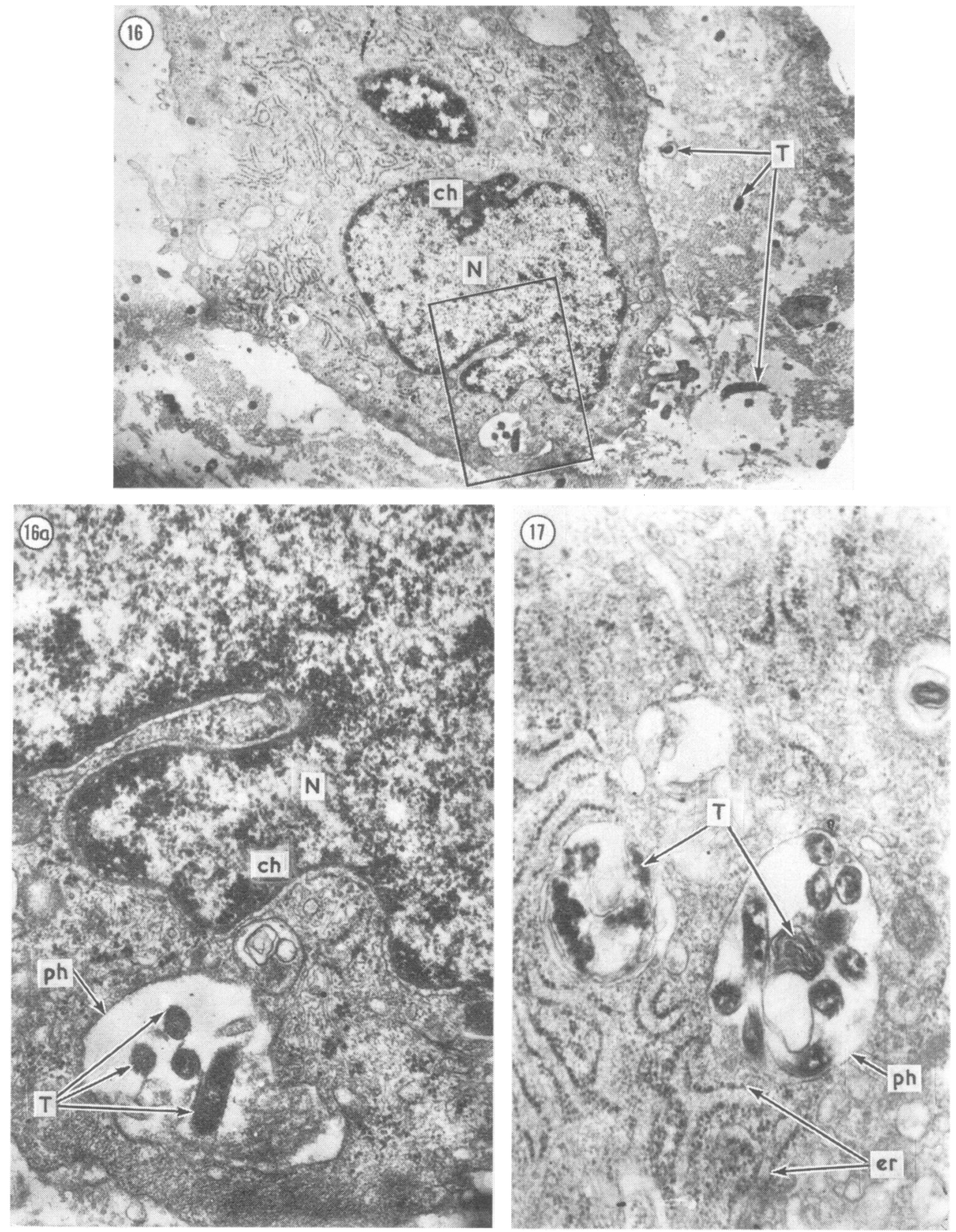

FIG. 16 Ultrathin section from a 6-week-old chancre taken 15 min. after administration of penicillin. Chromatin (ch) surrounds nuclear vacuoles (N) $\times \mathbf{8 , 0 0 0}$ FIG. $16 a$ Detail. $\times 25,000$

FIG. 17 Treponemes (T) in a phagosome (ph) in a state of lysis. $\times 25,000$ 

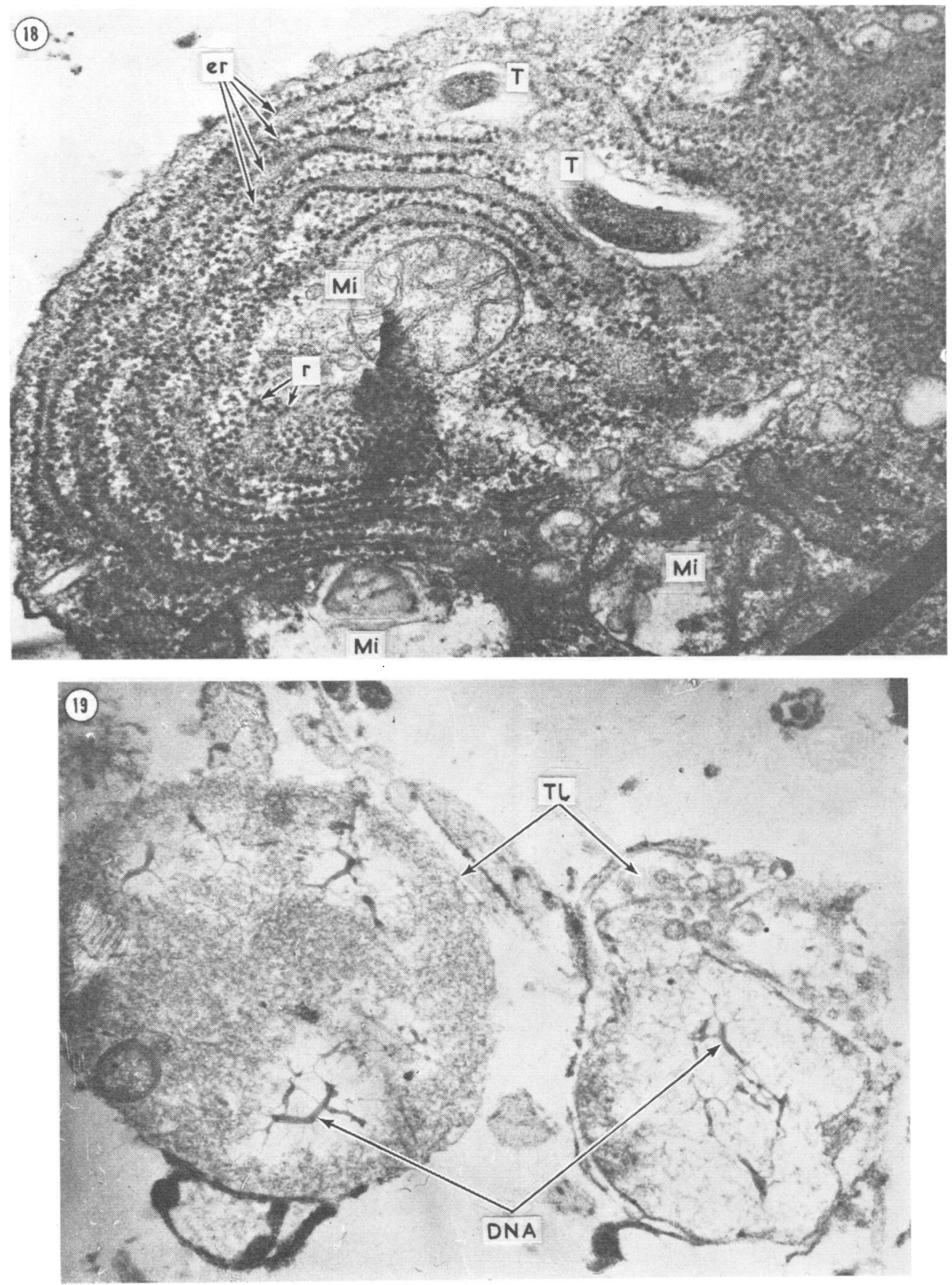

FIG. 18 T. pallidum inside plasma cells

FIG. $19 L$-forms of T. pallidum (TL) under the electron microscope, recalling the structure of a nucleus with strands of DNA. $\times 21,000$ 

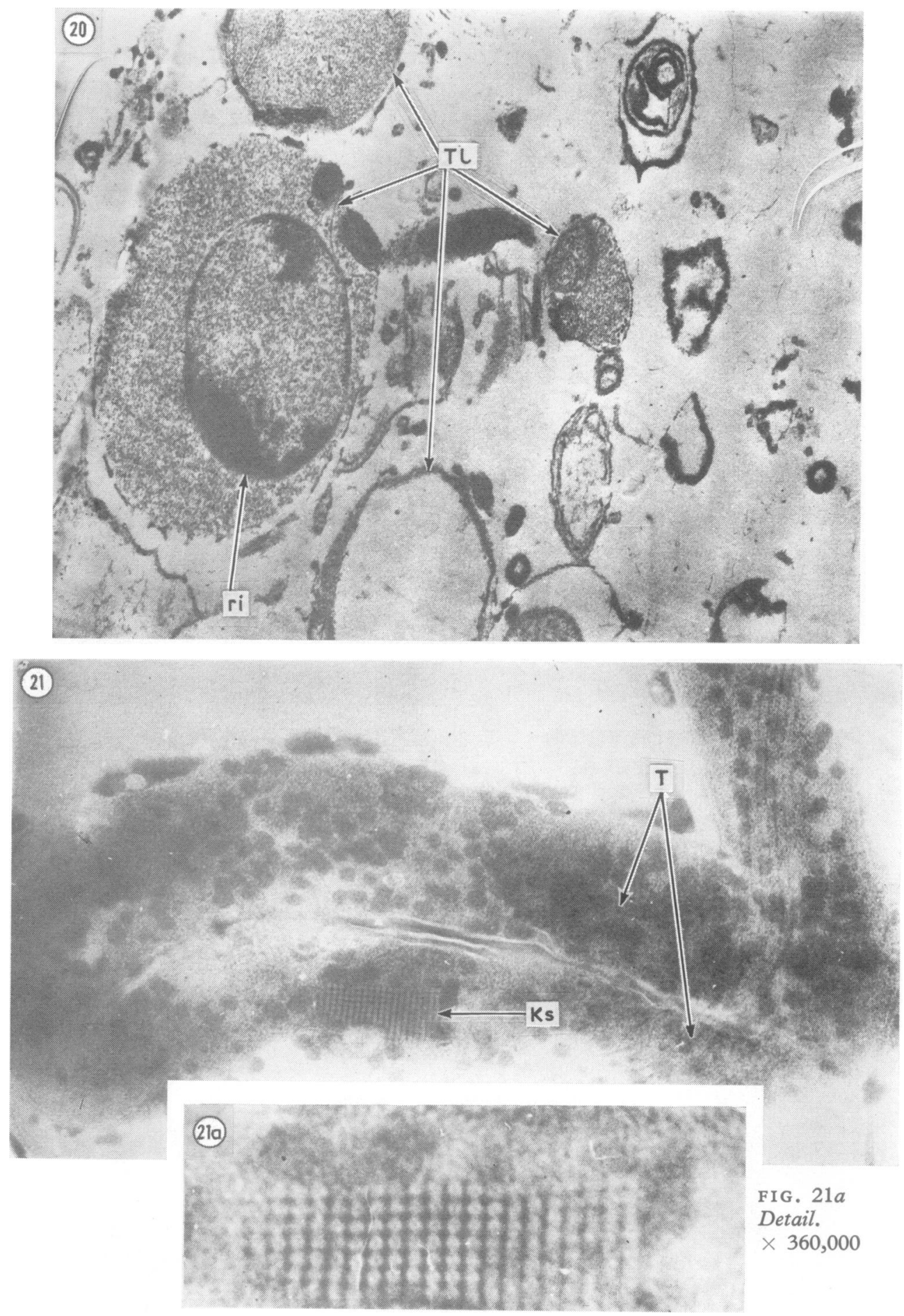

FIG. 20 L-forms of T. pallidum with different degrees of electron density. One contains a rounded inclusion (ri). $\times 21,000$

FIG. 21 T. pallidum Strain 8, showing a crystalloid structure (Ks) $\times 120,000$ 
orientated inwards facing the antigen. In plasma cells and macrophages, the treponemes are frequently covered with a kind of membranous sheath, and provided with dense envelopes. All this signifies that in plasma cells the treponemes are well protected, evade destruction, and may subsist for a long time. We have advanced the suggestion that the prolonged formation of antibodies and the persistence of positive serological reactions in syphilis may be explained by the presence of the antigen in plasma cells. This is especially likely since the latter may migrate into the blood vessels, be carried into distant organs little accessible to antibiotics, and exist there for a long time. Treponemes harboured in the cisternae of a plasma cell have been obtained from a rabbit with an 8-monthold chancre previously treated with penicillin.

Most treponemes reside in interstitial spaces, where great numbers of organisms are sometimes found.

Attention should be paid to the distribution of treponemes around blood vessels and sometimes even within the lumina. By way of the interstitial spaces the treponemes may gain access to the blood stream or penetrate from the vessels into the tissues. This fact explains the high incidence of treponemes in perivascular areas, where they are usually located extracellularly. The data obtained emphasize, moreover, the intimate interrelation between the lymphatic and the haematogenous routes. Moving along the lymphatic spaces the organisms may penetrate into the blood vessels.

The morphological appearance of $T$. pertenue in rabbit lesions and its interaction with the body cells are similar to the processes observed in syphilis, except for a more pronounced plasmocytic response, and more fully developed laminar membranes around the intra- and extracellular treponemes.

\section{$L-$ forms}

In collaboration with Dr L. M. Ustimenko we have produced experimentally L-forms of cultivated strain No. 8 (Ovčinnikov, Delektorskij, and Ustimenko, 1970).

Control photomicrographs made by phase contrast microscopy illustrate the original material, consisting of specimens typical for this strain. Subsequent photomicrographs demonstrate L-forms-large and small spherical bodies of variable density. In electron micrographs showing ultrathin sections of $\mathrm{L}$-forms, a thin membrane (Figs 19, 20) is visible, as well as formations varying in shape, dimension, and electron density. Some are homogenous, others granular, and still others have the structure of a nuclear vacuole. The L-forms of T. pallidum do not differ significantly in appearance from those of other organisms, for example, gonococcus, Proteus vulgaris, etc. When L-forms are transferred to the usual media they soon reverse to the original forms. For some time they may be found among typical treponemes, but subsequent preparations studied by phase contrast or electron microscopy show only ordinary forms of $T$. pallidum. Some of them are seen to divide. Fig. 20 shows a rounded inclusion (ri).

Thus it is evident that $T$. pallidum may produce $L-$ forms under conditions of stress. In our experiments the organisms were stressed with penicillin, various drugs, antisera, etc., and the addition of these agents led to the appearance of $\mathrm{L}$-forms. We have not yet isolated L-forms directly from animals affected with syphilis, but undoubtedly they can be present in rabbit tissues.

The significance of these data can hardly be overestimated if we recall that conversion to L-forms alters the clinical course of a disease, the virulence and pathogenicity of the organisms, their antigenic activity, drug resistance, and other properties, not to mention the diagnostic difficulties presented by such variants.

It should be noted that in some preparations of the treponemes we have found crystalloid structures (Ks), especially after the addition of penicillin (but also without it) and during the reversion of $L$-forms. The crystalloids had a three-dimensional symmetry and resembled protein paracrystals (Figs 21, 21a). The significance of these formations has not been established.

\section{Summary}

(1) Electron microscopy of $T$. pallidum has revealed a number of structural features: a sheath, a three-layered outer wall, a cytoplasmic membrane also consisting of three layers, superficial and deep bundles of fibrils, a nuclear vacuole, mesosomes, and ribosomes. Each of these formations has a complex structure.

(2) Transverse fission is the main mode of reproduction of $T$. pallidum. Under adverse conditions spherulation and encystment may be observed. The possibility of sexual reproduction cannot be excluded.

(3) The structure and motility of cysts, and the circumstances of their appearance, prove that encystment is an adaptive mechanism of survival.

(4) Under the action of penicillin or antiserum, $T$. pallidum in culture produces $\mathrm{L}$-forms, which reverse to the original spiral forms if transferred to media lacking these agents.

(5) In chancre tissues, $T$. pallidum may be located both inside and outside cells. Macrophages, plasma 
cells, endothelial cells, monocytes, and polymorphonuclear leucocytes actively participate in phagocytosis. As a rule, phagocytosis is not brought to completion (endocytobiosis predominates).

(6) Penicillin enhances cellular activity; after an injection complete phagocytosis may be demonstrated.

(7) The persistence of positive serological reactions may be explained by the prolonged presence of unaltered treponemes within plasma cells.

\section{References}

Ovčinnikov, N. M., and DelektorskiJ, V. V. (1966)

Bull. Wld Hlth Org., 35, 223

—— (1968) Brit. $\mathcal{F}$ vener. Dis., 44, 1

- (1969) Ibid., 45, 87

(1970a) Ibid., 46, 349

_- (1970b) Bull. Wld Hlth Org., 42, 437 , and UstimeNKo, L. M. (1970) 'L-forms of Treponema pallidum'. WHO/VDT/RES/70, 225

Prllot, J. (1965) Thèse, Série A, No. 4571, Lons-leSaunier, France

Ryter, A., and Pillot, J. (1963) Ann. Inst. Pasteur, 104, 496

Conceptions courantes sur la morphologie et la biologie du Treponema pallidum fondées sur la microscopie électronique

SOMMAIRE

(1) Les études du $T$. pallidum au microscope électronique ont révélé nombre de faits concernant sa structure: une gaîne, une paroi externe formée de trois couches, une membrane cytoplasmique consistant également en trois couches, des paquets de fibrilles superficielles et profondes, une vacuole nucléaire, des mesosomes et des ribosomes. Chacune de ces formations a une structure complexe.

(2) La séparation transversale est le principal mode de reproduction du $T$. pallidum. Lorsque les conditions sont défavorables, on peut observer la formation de sphères et de kystes. La possibilité de reproduction sexuée ne peut pas être exclue.

(3) La structure et la mobilité des kystes ainsi que les circonstances de leur apparition prouvent que l'enkystement est un mécanisme adapté à la survie.

(4) Sous l'action de la pénicilline ou d'un anti-sérum, le $T$. pallidum en culture produit des formes $\mathrm{L}$ qui retournent aux formes spiralées originelles après transport dans des milieux dépourvus des agents cités.

(5) Dans les tissus chancreux, le $T$. pallidum peut être détecté à la fois à l'intérieur et à l'extérieur des cellules. Les macrophages, les plasmocytes, les cellules endothéliales, les monocytes et les polynucléaires participent activement à la phagocytose. Habituellement, la phagocytose n'arrive pas à être totale (l'endocytobiose prédomine).

(6) La pénicilline stimule l'activité cellulaire; après une injection, une phagocytose complète peut être mise en évidence.

(7) La persistance de réactions sérologiques positives peut être expliquée par la présence prolongée de tréponèmes altérés à l'intérieur des plasmocytes. 